\title{
DIREITO E MORAL
}

\section{Mirian Gomes Canavarro Batista ${ }^{1}$}

\begin{abstract}
"O mundo moral, tal como aqui o entendemos como o remédio ao mal que o homem pode causar ao outro, nasce com a formulação, a imposição e a aplicação de mandamentos ou de proibições, e, portanto, do ponto de vista daqueles a quem são dirigidos os mandamentos e as proibições, de obrigações. Isso quer dizer que a figura deôntica originária é o dever, não o direito." Norberto Bobbio
\end{abstract}

\section{RESUMO}

O presente trabalho tem como escopo analisar o tema proposta pelo autor da obra Direito e Moral, Marcio Sotelo Felippe. Obra esta que serviu como ponto de partida para o seminário durante o semestre letivo do Curso de Mestrado da PUC/SP, crédito do Professor Doutor Pedro Serrano - Teoria Geral do Direito.

$\mathrm{O}$ autor começa com o questionamento de Píndaro, remontando à antiga Grécia e a discussão sobre Direito e Moral. Pergunta ele já na introdução: Qual é a lei soberana sobre nós? (costume, norma, natureza, razão).

A fim de responder tal pergunta vamos percorrer o panorama histórico dos grandes pensadores do direito e algumas das principais correntes jurisfilosóficas.

\footnotetext{
${ }^{1}$ Advogada, Mestranda em Direito Comercial pela PUC/SP
} 
Palavras-chave: Direito e Moral. Jusnaturalismo. Positivismo

\section{JUSNATURALISMO}

A melhor forma de entender um fato ou mesmo uma teoria é situá-la no contexto histórico. O homem, enquanto um ser que interage com o meio em que vive, transformando-o e sendo transformado, não pode ser visto isoladamente, sem qualquer influência externa na formulação e concretização de suas ideias.

Partindo desta premissa, entendemos que a concepção jusnaturalista foi o resultado de transformações econômicas e sociais que impactaram na concepção de poder do Estado.

O declínio das relações feudais de produção, a ascensão da burguesia, as revoltas camponesas e as guerras ocorridas durante o processo de formação do capitalismo propiciaram uma nova situação social, mesmo porque, ao contrário da nobreza, a burguesia não podia invocar o sangue e a família para justificar sua ascensão econômica. Os intelectuais do século XVII estavam preocupados em buscar respostas no âmbito da razão como justificativa do poder do Estado, fomentando a discussão sobre a origem do Estado. Não se tratava, porém de uma busca histórica, mas sim de uma explicação lógica que justificasse a ordem social representada pelos interesses da ascendente burguesia.

Pois bem, se a filosofia é constituída por uma razão prática, qual seja a moral, não podemos nos limitar a responder apenas questionamentos relativos do ser, mas nos sentimos instigados a ir além, a buscar a resposta do que devemos fazer.

O moralmente correto, a conduta boa, a vida coletiva com interesses comuns se consubstanciam no senso de justiça e para exemplificar tal assertiva o autor recorre à Apologia de Sócrates. O cerne da obra produzida por Platão é o discurso em defesa de Sócrates. O filósofo, contrariando a lei da época, clama em sua defesa o seu senso de justiça sustentando que era seu dever correr perigo ao lado da lei e da justiça ao compactuar com a injustiça. A justiça de Sócrates estava arraigada em seu juízo moral e confrontava a justiça imposta à época. Antígona também ousa descumprir a ordem da polis em nome da moral, 
acreditando que sem os ritos fúnebres seu irmão teria que vagar 100 anos à margem do rio dos mortos. Antígona submete a regra da cidade a um juízo moral e vê-se vinculada apenas a esse juízo, ela pensa e age de acordo com um padrão jusnaturalista.

Nesse momento histórico o direito natural não mais deriva da natureza cósmica ou da natureza da sociedade como acontecia com o direito natural aristotélicotomista, mas sim da natureza do homem individual e da observação daqueles impulsos que o levavam à ação ${ }^{2}$.

Para entender os conceitos do jusnaturalismo tomamos a liberdade de transcrever os ensinamentos de Norberto Bobbio. Para ele, "a ideia de que o homem enquanto tal tem direitos, por natureza, que ninguém (nem mesmo o Estado) lhe pode subtrair, e que ele mesmo não pode alienar (mesmo que, em caso de necessidade, ele os aliene, a transferência não é válida), essa ideia foi elaborada pelo jusnaturalismo moderno. Seu pai é John Locke. Segundo Locke, o verdadeiro estado do homem não é o estado civil, mas o natural, ou seja, o estado de natureza no qual os homens são livres e iguais, sendo o estado civil uma criação artificial, que não tem outra meta além da de permitir a mais ampla explicitação da liberdade e da igualdade naturais ${ }^{3}$."

Explica o autor que a doutrina filosófica que fez do indivíduo, e não mais da sociedade, o ponto de partida para a construção de uma doutrina da moral e do direito foi o jusnaturalismo, que pode ser considerado, conforme nos informa, sob muitos aspectos a secularização da ética cristã. Nesse diapasão, partindo de Locke, pode-se compreender como a doutrina dos direitos naturais pressupõe uma concepção individualista da sociedade e, portanto, do Estado.

Em relação aos indivíduos, doravante, primeiro vêm os direitos, depois os deveres; em relação ao Estado, primeiro os deveres, depois os direitos. A mesma inversão ocorre com relação à finalidade do Estado, a qual, para o organicismo, é a concórdia ciceroniana (a omónoia dos gregos), ou seja, a luta contra as facções que, dilacerando o corpo

\footnotetext{
${ }^{2}$ HESPANHA, Antonio Manoel, Panorama histórico da cultura jurídica européia, Publicações Europa-América, $2^{a}$ Ed., Portugal, p.151

${ }^{3}$ Bobbio, Norberto, 1909-A era dos direitos / Norberto Bobbio; tradução Carlos Nelson Coutinho; apresentação de Celso Lafer. — Nova ed. — Rio de Janeiro: Elsevier, 2004. — $7^{\mathrm{a}}$ reimpressão, p.18
}

http://revistasapereaude.org/index.php/edicoes/ano-5-volume-1-agosto-2016 
político, o matam; e, para o individualismo, é o crescimento do indivíduo, tanto quanto possível livre de condicionamentos externos ${ }^{4}$."

A partir desse raciocínio trazemos á tona o egoísmo como caraterística do ser humano - egoísta e solitário - contrariando a ideia de Aristóteles de que o homem é um animal político. Em que pese afirmação de Hobbes que "o homem é o lobo do homem" o próprio autor esclarece que no estado de natureza nenhum homem é capaz de dominar outro, por esta razão, permanecem em constante estado de guerra.

É importante ressaltar aqui que, naquele momento histórico, a Inglaterra vivia grandes turbulências no plano político, uma guerra civil entre rei e parlamento, fato que não pode ser desprezado, e que, certamente, deve ter inspirado o filósofo na elaboração de sua teoria, cuja visão de estado natural, embora teórica, retrata indubitavelmente aquele momento da Inglaterra.

Hobbes, para solucionar esse problema, prima pela necessidade de um contrato entre os homens, que dá origem ao Estado civil (social) de completa submissão. A teoria do contrato social deu origem às teorias democráticas que tiveram sua conclusão na Revolução Francesa. Tal teoria também fundamentou o despotismo iluminado - típico das monarquias e principados europeus do século XVIII 5 .

Nessa seara o jusnaturalismo se desdobrou em duas grandes vertendes, quais sejam: a demo liberal - de John Locke e a absolutista, inaugurada por Thomas Hobbes.

\section{POSITIVISMO JURÍDICO}

A condição específica do Estado moderno decorre dos chamados três monopólios: o monopólio da força ou coerção, o monopólio da tributação e o monopólio da norma jurídica.

O positivismo jurídico e a expressão teórica do atributo do monopólio da norma jurídica pelo Estado. Assim, podemos definir o positivismo jurídico como o conceito segundo o qual o Direito é constituído pelas normas eficazes ou válidas em uma sociedade, sendo o conteúdo aberto e discricionário.

\footnotetext{
${ }^{4}$ Bobbio, Norberto, 1909-A era dos direitos / Norberto Bobbio; tradução Carlos Nelson Coutinho; apresentação de Celso Lafer. — Nova ed. — Rio de Janeiro: Elsevier, 2004.— $7^{\mathrm{a}}$ reimpressão

${ }^{5}$ HESPANHA, Antonio Manoel, Panorama histórico da cultura jurídica européia, Publicações Europa-América,

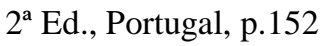

http://revistasapereaude.org/index.php/edicoes/ano-5-volume-1-agosto-2016 


\subsection{KELSEN}

$\mathrm{Na}$ visão de Kelsen, o fundamento de validade do direito estaria na hierarquia normativa, havendo a subordinação de normas inferiores a outras superiores. Analisando dentro desta concepção, inclusive a Lei do Reich seria legítima, em razão da chancela do Estado, validando tal legislação positiva. Sob essa ótica, seria inegável a contribuição kelseniana à justificação do totalitarismo:

"Segundo o Direito dos Estados totalitários, o governo tem poder para encerrar em campos de concentração, forçar a quaisquer trabalhos e até matar os indivíduos de opinião, religião ou raça indesejável. Podemos condenar com a maior veemência tais medidas, mas o que não podemos é considerá-las como fora da ordem jurídica desses Estados". (KELSEN, 1996, p.44)

Consubstanciado no impacte das palavras acima, resta-nos a dúvida: Kelsen faz alguma relação entre direito e moral? Sim, nesta relação está inserida a relação entre direito e justiça, que segundo ele é uma "exigência da moral". Como nos explica o professor Lopes Colpani $^{6}$, no prefácio à segunda edição da "Teoria Pura do Direito", lê-se: "O problema da justiça, enquanto problema valorativo situa-se fora de uma teoria do Direito que se limita à análise do Direito positivo como sendo a realidade jurídica". ${ }^{7}$ Kelsen remete o assunto para a política jurídica em apêndice à “Teoria Pura do Direito". Sendo a mais importante obra de Kelsen foi, por muitos, considerada o mote legitimador do Nazismo. A teoria simplificada tudo à norma, ou seja, uma conduta estaria, portanto, em conformidade com a norma posta, com um dever ser, não havendo normas justas ou injustas, mas válidas ou inválidas ${ }^{8}$.

\footnotetext{
6 In Revista Novos Estudos Jurídicos - Num 7-14, Abril de 2002 - acesso online: http://livros-erevistas.vlex.com.br/vid/eacute-tica-kant-kelsen-schopenhauer-59319616

${ }^{7}$ KELSEN, Hans. Teoria pura do direito, p. 68.

8 "Neste sentido, embora se possa acusar a teoria pura do direito de aceitar tudo o que provém da vontade do Estado, o certo é que o seu sentido mais profundo é o de constituir um manifesto contra os totalitarismos políticos do seu tempo, que num sentido ou noutro, procuravam funcionalizar o direito em relação às conveniências do poder, legitimando-o a partir de considerações políticas como o domínio de classe (estalinismo) ou as necessidades vitais de uma raça (nacional-socialismo)."
} 


\subsection{KANT}

Os horrores do Estado Nazista colocaram em cheque a hegemonia teórica do positivismo. Houve uma reação que questionava o limite moral que, uma vez ultrapassado, determinava que uma norma posta pelo Estado não integrava o conceito de direito. Assim, ressuscitava a ideia de um Direito superior à lei, um padrão para medir leis positivas e considera-las contrárias ao direito. Ressurge com força o princípio da dignidade humana sendo elevado à condição e princípio jurídico. A essa aproximação entre moral e direito ou a necessidade de uma fundamentação moral para o direito denominou-se "virada kantiana".

O escopo de Kant, no momento da fundamentação da moralidade, era encontrar e fixar uma lei moral objetiva, válida independente deste ou daquele indivíduo, desta ou daquela particularidade, ou seja, universal.

Segundo Kant, a autonomia da vontade é imprescindível à moralidade da ação e a vontade é autônoma quando é determinada pela lei moral que ela dá a si mesma; logo, se a vontade for determinada por qualquer outro motivo externo a ela, é heterônoma e, assim, deixa de ser vontade moral. Vejamos o que diz Norberto Bobbio:

"É notória a importância que tem a distinção entre autonomia e heteronomia, para a distinção da moral de Kant. Segundo Kant, a vontade moral ou é autônoma ou não é moral: qualquer objeto que determine a vontade de maneira heterônoma, tira à vontade e à ação que deriva disso a qualidade de moral. Todos os sistemas morais tradicionais que colocaram como fim da vontade humana ou a perfeição ou a felicidade, ou qualquer outro bem, são ilegítimos: não entenderam o caráter profundo e autêntico da moralidade."

A autonomia do homem se expressa na sua capacidade de autodeterminação, na sua vontade legisladora de estabelecer e alcançar determinados fins no mundo social. Isso implica que toda a legislação oriunda da vontade legisladora do ser humano necessita ter como finalidade o homem, ou mais especificamente, a vida e a dignidade do ser humano.

Nesse sentido, o imperativo categórico orienta-se segundo um valor fundamental e universal, a saber: a dignidade humana. Segundo Kant:

(...) É que o princípio de toda a legislação prática reside objetivamente na regra e na forma da universalidade que a torna capaz de ser uma lei 
(sempre lei da natureza); subjetivamente, porém, reside no fim; mas o sujeito de todos os fins é todo o ser racional como fim em si mesmo: daqui resulta o terceiro princípio prático da vontade como condição suprema da concordância desta vontade com a razão prática universal, quer dizer a ideia da vontade de todo o ser racional concebida como vontade legisladora universal ${ }^{9}$.

Assim, para Kant, a autonomia da vontade é a propriedade da vontade de ser lei para si mesma, e o princípio da autonomia encontra-se na escolha de máximas que estejam compreendidas, concomitantemente, como leis universais, no ato de querer: Autonomia da vontade é aquela sua propriedade graças à qual ela é para si mesma a sua lei (independentemente da natureza dos objetos do querer). O princípio da autonomia é portanto: não escolher senão de modo a que as máximas da escolha estejam incluídas simultaneamente, no querer mesmo, como lei universal ${ }^{10}$.

$\mathrm{Na}$ visão de Kant, o homem, em função de constituir o único ser detentor de uma capacidade racional que o distingue dos demais seres da natureza, não pode contar entre as coisas que possuem um preço, porém, unicamente como um ser que conta uma dignidade. Tal dignidade que é conferida a todo homem por causa de suas faculdades racionais, desenvolvidas e possibilitadas pela liberdade, torna-o também um ente sujeito à lei moral, que, conforme já explanado, é a única que pode mostrar ao homem sua liberdade prática.

\subsection{KELSEN EKANT}

Concluímos que enquanto Kant busca um fundamento absoluto para moral, Kelsen rebate essa linha de raciocínio, negando um fundamento absoluto ao valor moral, admitindo a existência de uma norma fundamental, valorando a ética e o direito.

\footnotetext{
${ }^{9}$ KANT, I. Fundamentação da metafísica dos costumes. Trad. Paulo Quintela. Lisboa: Edições 70, 1995. Cotejada com a tradução de Guido Antônio de Almeida. São Paulo: Barcarola Discurso Editorial, 2009.

${ }^{10}$ KANT, I. Fundamentação da metafísica dos costumes. Trad. Paulo Quintela. Lisboa: Edições $70,1995$. Cotejada com a tradução de Guido Antônio de Almeida. São Paulo: Barcarola Discurso Editorial, 2009, p 85
} 
Um por buscar os fundamentos e outro por tentar demonstrar a inutilidade de buscálos, acabam colocando como fecho de seu sistema moral e jurídico, leis universais pressupostas e boas em si mesmas, cuja pureza as encaixaria em qualquer sociedade ${ }^{11}$.

Em que pesem os ensinamentos de Kant e Kelsen e tudo que surgiu a partir daí, conforme as palavras de Norberto Bobbio, o conceito de moral é problemático. Com uma clareza sublime, o autor nos leva a pensar ao afirmar que uma coisa é o progresso científico e técnico, outra é o progresso moral. Não se trata, prossegue, de retomar a antiga controvérsia sobre a relação entre um e outro. Limita-se a dizer que, enquanto parece indubitável que o progresso técnico e científico é efetivo, tendo mostrado até agora as duas características da continuidade e da irreversibilidade, bem mais difícil — se não mesmo arriscado — é enfrentar o problema da efetividade do progresso moral, pelo menos por duas razões assim o crê (i) o próprio conceito de moral é problemático; (ii) ainda que todos estivéssemos de acordo sobre o modo de entender a moral, ninguém até agora encontrou "indicadores", para medir o progresso moral de uma nação, ou mesmo de toda a humanidade, tão claros quanto o são os indicadores que servem para medir o progresso científico e técnico ${ }^{12}$.

Apesar de afirmar a problemática de se tentar conceituar a moral, Bobbio não pretende propor uma solução, mas sim, nos presenteia com sua opinião:

"o modo mais útil para nos aproximarmos do problema, qual é o modo, também pedagogicamente mais eficaz, para fazer compreender a natureza doproblema, dando assim um sentido àquele conceito obscuríssimo, salvo para uma visão religiosa do mundo (mas aqui busco encontrar uma resposta do ponto de vista de uma ética racional), que é habitualmente designado com a expressão "consciência moral". $\mathrm{Na}$ verdade, Kant dizia que, juntamente com o céu estrelado, a consciência moral era uma das duas coisas que o deixavam maravilhado; mas a maravilha não só não é uma explicação, mas pode até derivar de uma ilusão e gerar, por sua vez, outras ilusões. O que nós chamamos de "consciência moral", sobretudo em função da grande (para não dizer exclusiva) influência que teve a educação cristã na formação do homem europeu, é algo relacionado com a formação e o crescimento da consciência do estado de sofrimento, de indigência, de penúria, de miséria, ou, mais geralmente, de infelicidade, em que se

\footnotetext{
${ }^{11}$ SCHOPENHAUER, Arthur. O mundo como vontade e representação. Crítica a filosofia Kantiana. São Paulo: Nova Cultural, 2000.

${ }^{12}$ Bobbio, Norberto, 1909- A era dos direitos / Norberto Bobbio; tradução Carlos Nelson Coutinho; apresentação de Celso Lafer. - Nova ed. — Rio de Janeiro: Elsevier, 2004. — $7^{\mathrm{a}}$ reimpressão, p.28
}

http://revistasapereaude.org/index.php/edicoes/ano-5-volume-1-agosto-2016 
encontra o homem no mundo, bem como ao sentimento da insuportabilidade de tal estado."

\section{PÓS - POSITIVISMO}

Após o período de autocrítica do positivismo diante da barbárie nazista, alguns autores sustentaram uma conexão necessária entre moral e direito que não se limitava aos casos de injustiça ou horror mas que poderiam ser demonstrados na prática cotidiana. Decisões flagrantemente apartadas da justiça, como as que permearam o facismo e o nazismo, não mais poderiam ser aceitas. A sociedade percebeu que, "senão houver na atividade jurídica um forte conteúdo humanitário, o direito pode servir para justificar a barbárie praticada em nome da lei (...), o legislador, mesmo representando uma suposta maioria, pode sertão opressor que o pior dos tiranos."13

A crise do positivismo e seu declínio podem ser constatados pela sucumbência da ideia de completude do sistema positivo codificado e pelas dificuldades conter a aplicação das normas positivas mesmo pela evidente má-utilização (como pela Nazismo). O positivismo jurídico tradicional passa a não ser capaz "de explicar adequadamente a realidade do direito $^{14 \%}$.

\section{KARL MARX}

Na contramão dos positivistas e sua forma coercitiva de aplicação da lei, os póspositivistas procuravam demonstrar uma conexão necessária entre moral e direito. Dentre todos, merece destaque Karl Mar e sua habilidade para desnudar a natureza do direito na sociedade capitalista. Com sua obra o Manifesto do Partido Comunista (1848), inflamou a classe trabalhadora contra o capitalismo. O pensamento do autor visa armar ideologicamente

\footnotetext{
${ }^{13}$ MARMELSTEIN, George. Curso de Direitos fundamentais. São Paulo: Atlas, 2008.p.10 ${ }^{14}$ FIGUEROA, Alfonso García. Criaturas de la moralidad: una aproximación neo constitucionalista al Derecho a través de los derechos. Madrid: Trotta, 2009ª , p. 228-229 
o proletariado; demonstrar com rigor científico a injustiça essencial do sistema e incitar a classe dominada a lutar por reformas político-econômico-sociais ${ }^{15}$.

Ao contrário dos modos de produção anteriores, escravagista e feudal, o trabalhador no capitalismo é autônomo, sujeito de direito e negocia sua força de trabalho. Há então uma igualdade jurídico-formal e a relação entre ele e o proprietário dos meios de produção é contratual, um novo tipo de relação: direito com direito.

Explica Marcio Sotelo Felippe que o Estado tem uma função na estrutura do modo de produção capitalista, que decorre daquilo que Marx expressa como "antinomia direito contra direito"; esta expressão tem um mundo de significados. Nisto que reside a especificidade do capitalismo como modo de produção, por isso se desvenda o sentido do Estado, a necessidade do seu monopólio da norma jurídica e sua aparente autonomia que resultam afinal, em um meio de dominação.

O processo histórico de lutas sociais levou a um direito de ter direitos e isto pode se vislumbrar uma dimensão de moralidade. O capitalismo abre a possibilidade do direito de ter direitos. O processo de construção dos direitos é pós convencional: normal que, a despeito do fato da estrutura capitalista e dos correspondentes juízos convencionais, atenuam a desigualdade e conferem poderes aos que estão abaixo da escala social.

Sendo assim, quando falamos da cidadania, direitos, dignidade humana, estamos falando desta moralidade possível em um modo de dominação capitalista.

Surge a construção de decisões através de princípios - que quando atuam subordinam as regras, são uma forma de raciocínio superior, mais sofisticado e dão, pela dimensão moral, uma racionalidade que legitima ou não a regra. Inicia-se uma nova era - a do Capital e suas nuances de poder e submissão.

\section{CONCLUSÃO}

15 Marselha Silvério de Assis, Direito, Estado e sociedade sob a óptica de Karl Marx, disponível em https://jus.com.br/artigos/15111/direito-estado-e-sociedade-sob-a-optica-de-karl-marx 
Neste ponto, nos resta a audácia de responder ao questionamento lançado lá no início do trabalho. Se nos falta conhecimento, nos sobra admiração pela obra de Bobbio, refutando a ele o desafio que assim nos ensina, encerrando - mesmo que momentaneamente - o debate:

O mundo moral, tal como aqui o entendemos — como o remédio ao mal que o homem pode causar ao outro, nasce com a formulação, a imposição e a aplicação de mandamentos ou de proibições, e, portanto, do ponto de vista daqueles a quem são dirigidos os mandamentos e as proibições, de obrigações. Isso quer dizer que a figura deôntica originária é o dever, não o direito ${ }^{16}$.

\section{BIBLIOGRAFIA}

ASSIS, Marselha Silvério de, Direito, Estado e sociedade sob a óptica de Karl Marx, disponível em https://jus.com.br/artigos/15111/direito-estado-e-sociedade-sob-a-optica-dekarl-marx

BOBBIO, Norberto, 1909- A era dos direitos / Norberto Bobbio; tradução Carlos Nelson Coutinho; apresentação de Celso Lafer. — Nova ed. — Rio de Janeiro: Elsevier, 2004. — $7^{\mathrm{a}}$ reimpressão, p.29.

FERNANDES, Ricardo Vieira de Carvalho e Guilherme Pereira Dolabella Bicalho - Do positivismo ao pós-positivismo jurídico http://www2.senado.leg.br/bdsf/bitstream/handle/id/242864/000910796.pdf?sequence=1

FIGUEROA, Alfonso García. Criaturas de lamoralidad: una aproximación neo constitucionalista al Derecho através de los derechos. Madrid: Trotta, 2009.

KANT, I. Fundamentação da metafísica dos costumes. Trad. Paulo Quintela. Lisboa: Edições 70, 1995. Cotejada com a tradução de Guido Antônio de Almeida. São Paulo: Barcarola Discurso Editorial, 2009

KELSEN, Hans. Teoria pura do direito. São Paulo: Martins Fontes, 1998.

MARMELSTEIN, George. Curso de Direitos fundamentais. São Paulo: Atlas, 2008.

\footnotetext{
${ }^{16}$ Bobbio, Norberto, 1909- A era dos direitos / Norberto Bobbio; tradução Carlos Nelson Coutinho; apresentação de Celso Lafer. - Nova ed. — Rio de Janeiro: Elsevier, 2004. — $7^{\text {a }}$ reimpressão, p.29
} 
SCHOPENHAUER, Arthur. O mundo como vontade e representação. Crítica a filosofia Kantiana. São Paulo: Nova Cultural, 2000. 